Recepción: 20 / 04 / 2017

Aceptación: 20 / 05 / 2017

Publicación: 15 / 07 / 2017

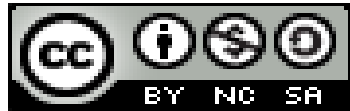

Ciencias Sociales y Políticas

Artículo Científico

\title{
Acción extraordinaria de protección, el debido proceso, la seguridad jurídica, en las notificaciones procesales
}

\section{Extraordinary action of protection, due process, legal certainty, in procedural notifications}

\section{Ação extraordinária de proteção, devido processo, a segurança jurídica, as notificações processuais}

\author{
Daniel E. Gómez-Márquez I \\ Daniel.gomezm@gmail.com \\ Susana B. Cedeño-Solórzano II \\ susanabc.s@gmail.com \\ Carlos G. Vásquez-Morales III \\ carlos_vazquez@gmail.com
}

Correspondencia: Daniel.gomezm@gmail.com

I. Abogado de los Tribunales y Juzgados de la República del Ecuador; Ingeniero Comercial y Empresarial, Universidad de Guayaquil, Guayaquil, Ecuador.

II. Master Internacional en Turismo; Magister en Gobernabilidad y Gerencia Política; Licenciada en Ciencias de la Comunicación Social; Abogada de los Tribunales y Juzgados de la República del Ecuador, Universidad de Guayaquil, Guayaquil, Ecuador.

III. Magister en Derechos Fundamentales y Justicia Constitucional; Especialista en Procedimientos Constitucionales; Diploma Superior en Derecho Constitucional y Derechos Fundamentales; Abogado de los Tribunales y Juzgados de la República del Ecuador; Doctor en Jurisprudencia, Universidad de Guayaquil, Guayaquil, Ecuador. 


\section{Resumen}

El objetivo de este estudio es determinar que al no tomar en cuenta la notificación de una parte procesal puede acarrear una responsabilidad jurídica ya que la justicia no se celebraría como debe ser y esta no sería eficaz, desgastado así el aparato estatal ocupando tiempo y espacio en un proceso que no será exitoso por la inobservancia de cosas elementarles.

Por qué en el presente caso se pretende que se declare la vulneración de derechos constitucionales al debido proceso, incluyendo el derecho a la defensa y que se disponga la reparación integral de los mismos y la invalidez del auto.

La Convención Americana sobre Derechos Humanos, de la que son parte la mayoría de los Estados americanos, establece la eficacia vinculante de las resoluciones de la Corte: compete a esta interpretar y aplicar lo que establécela Convención como otros instrumentos que le reconocen competencia: Protocolo de San Salvador y Convenciones sobre tortura y desaparición forzada y acerca de violencia contra la mujer en ejercicio de su competencia Los Estados Partes en la Convención se comprometen a cumplir la decisión de la Corte en todo caso en que sean partes.

"Un medio de controlar la razonabilidad de las leyes" (Zabala, 2012). Esto hace referencia a la tutela de los derechos esenciales del individuo frente al arbitrio del poder público en el ámbito ejecutivo y legislativo, no solo en el instrumental o procesal.

Palabras claves: Constitución; derechos humanos; tribunal superior de conciliación y arbitraje; derechos laborales; consorcio vachagnon. 


\begin{abstract}
The objective of this study is to determine that by not taking into account the notification of a procedural party can carry a legal responsibility since justice would not be held as it should be and this would not be effective, thus worn out state apparatus occupying time and space in A process that will not be successful due to the nonobservance of elementary things.

Why this case is intended to declare the violation of constitutional rights to due process, including the right to a defense and to provide for integral reparation of the same and the invalidity of the order.
\end{abstract}

The American Convention on Human Rights, to which most of the American States are parties, establishes the binding effect of the decisions of the Court: it is up to it to interpret and apply what establishes the Convention as other instruments that recognize jurisdiction; San Salvador and Conventions on torture and forced disappearance and on violence against women in exercise of their jurisdiction The States Parties to the Convention undertake to comply with the decision of the Court in any case to which they are parties.

"A means of controlling the reasonableness of laws" (Zabala, 2012). This refers to the protection of the essential rights of the individual against the arbitration of public power in the executive and legislative sphere, not only in the instrumental or procedural.

Key words: Constitution; human rights; high court of conciliation and arbitration; labor rights; vachagnon consortium. 


\section{Resumo}

O objetivo deste estudo é determinar que, não tendo em conta a notificação de uma parte processual pode trazer uma responsabilidade legal e que a justiça não teria lugar como deveria ser e isso não seria eficaz, aparelho de estado desgastado bom tempo ocupando e espaço um processo que não será bem sucedido por falta de observar elementarles coisas.

Por que, neste caso, pretende-se que a violação do devido processo constitucional declaração de direitos, incluindo o direito de defesa e do reparaciónintegral mesmo e nulidade do auto torna disponível.

A Convenção Americana sobre Direitos Humanos, que são parte da maioria dos Estados americanos, estabelece o carácter vinculativo das decisões do Tribunal: uma questão para a interpretação e aplicação que estabelecê-lo Convenção e outros instrumentos que reconhecem a competência: Protocolo San Salvador e convenções sobre tortura e desaparecimento forçado e sobre a violência contra as mulheres no exercício da jurisdição dos Estados partes na Convenção comprometem-se a cumprir a decisão da Corte em todo caso em que forem partes.

"Um meio de controlar a razoabilidade das leis" (Zabala, 2012). Isso se refere à protecção dos direitos fundamentais do indivíduo contra o poder discricionário das autoridades públicas no nível executivo e legislativo, não só no instrumental ou processual.

Palavras-chave: Constituição; direitos humanos; tribunal de conciliação e arbitragem superior; direitos do trabalho; vachagnon de consórcio. 
Acción extraordinaria de protección, el debido proceso, la seguridad jurídica, en las notificaciones procesales

\section{Introducción}

El presente tema que ha sido objeto de estudio de caso se basa en la acción extraordinaria de protección, garantía constitucional consagrada en la constitución vigente de Ecuador así mismo en la Ley orgánica de garantías jurisdiccionales y control constitucional para decidirme por ése tema y después de un análisis extenso de los conceptos más importantes desde el origen de la Constitución, elementos, reforma, estructura, tipos de constitución en forma general y en la República del Ecuador ya que nuestro país ha venido generando un sin número de cambios o reformas en la carta magna que nos rige, la historia nos dice que desde los inicios de la Gran Colombia en la República del Ecuador hasta la actualidad se han desarrollado veinte constituciones, unas que marcaron más la historia constitucional de nuestro país, así como también otras que no pudieron entrar en vigencia por ser derogadas.

El presente caso trata de la importancia de las notificaciones a los sujetos procesales dentro de un litigio, ya que es un paso medular, porque de éste depende que el proceso legal sea justo equitativo y en igualdad de condiciones, el señor SAMUEL REYES PUGA interpuso una acción extraordinaria ya que la ley orgánica de garantías jurisdiccionales y control constitucional, su objeto y finalidad de ésta ley es regular la jurisdicción constitucional, con el fin de garantizar jurisdiccionalmente los derechos reconocidos en la Constitución y en los instrumentos internacionales de derechos humanos y de la naturaleza; y garantizar la eficacia y la supremacía constitucional.

La siguiente acción es producto de un litigio proviene de lo laboral, entre un conflicto entre el comité especial de trabajadores del consorcio VACHAGNON y los representantes de la empresa, 
el conflicto colectivo de trabajo se sustancio ante el Director Regional de Trabajo y Presidente del Tribunal superior de Conciliación y Arbitraje.

\section{Materiales y métodos}

En nuestro estudio de caso utilizamos El método inductivo es aquel método científico que obtiene conclusiones generales a partir de premisas particulares. Se trata del método científico más usual, con respecto a nuestro tema se podrá apreciar en cuatro pasos esenciales: la observación de los hechos para su registro; la clasificación y el estudio de estos hechos; la derivación inductiva que parte de los hechos y permite llegar a una generalización; y la contrastación. Ya que por medio del auto dictado el 4 de abril del 2011, por el Tribunal Superior de Conciliación y Arbitraje, en el conflicto suscitado entre el Comité Especial de Trabajadores del Consorcio Vachagnon contra su Empleador, vulnera el derecho a la tutela efectiva, imparcial y expedita, consagrada en el artículo 75 de la Constitución La Corte Constitucional ha señalado que el derecho a la tutela judicial efectiva tiene una doble dimensión: por un lado, el derecho de las personas a acceder a la administración de justicia sin restricciones, y por otro lado, el deber de la autoridad jurisdiccional de garantizar el ejercicio de los derechos de los sujetos procesales.

El derecho a la tutela judicial efectiva, imparcial y expedita, comporta un derecho de las personas de acceso a la justicia y el deber de los operadores judiciales de ajustar sus actuaciones a los parámetros legales y constitucionales pertinentes; de esta manera, se configura el derecho de manera integral en donde los jueces y juezas asumen el rol de ser garantes del respeto de los derechos que les asisten a las partes dentro de un proceso determinado

En suma, la tutela judicial efectiva equivale al derecho de las personas para exigir en vía jurisdiccional que mediante el cumplimiento del debido proceso, se proteja de forma inmediata sus 
Acción extraordinaria de protección, el debido proceso, la seguridad jurídica, en las notificaciones procesales

derechos, cuando estos son amenazados o vulnerados; y correlativamente, el derecho a que la petición de exigencia sea atendida en el tiempo y la forma que establece la ley por los órganos de justicia. Vale resaltar que el contenido del derecho a la tutela judicial efectiva es muy amplio, y despliega sus efectos en tres momentos distintos: primero, al acceder a la justicia; segundo, durante el desarrollo del proceso; y finalmente, al tiempo de ejecutarse la sentencia.

Frente a este escenario, conviene analizar si el auto que se impugna vulneró o no el derecho a la tutela judicial efectiva, considerando las precisiones anotadas precedentemente.

\section{Resultados.}

Hay que apuntar que el auto que se acusa, no solo ordenó el pago de liquidaciones al CONSORCIO V ACHAGNON, a favor de los trabajadores, sino también amplió la responsabilidad solidariamente a las compañías AGRO INDUSTRIAL V ALANGO S. A., y GROUPE CHAGNON INTERNATIONAL L TEE, a sus representantes legales por sus propios derechos y por los que representan en la compañía, mismas que nunca fueron partes procesales y por lo tanto tampoco fueron notificadas con el pliego de peticiones realizado por los trabajadores del Consorcio Vachagnon, lo que ocasionó que fueran condenadas dentro de un proceso en el que no se respetó su derecho a la defensa y a la tutela judicial efectiva y por ende a la seguridad jurídica, Esta situación ocasionó el embargo de bienes de terceras personas que no fueron parte del proceso de arbitraje y mediación, desconociendo el derecho consagrado en el artículo 75 de la Constitución6 , que corresponde al derecho que tiene toda persona de acceder gratuitamente a la justicia y a la tutela efectiva, imparcial y expedita de sus derechos e intereses, con sujeción a los principios de inmediación y celeridad. 
Así también, cabe señalar que los vocales que suscribieron el auto de ampliación confunden principios constitucionales, como el carácter normativo superior de la Constitución y la aplicación directa de la Constitución, al confrontarlas con los derechos irrenunciables de los trabajadores y el principio "in dubio pro labore", ya que ninguno de los principios y derechos se encuentran en conflicto entre sí; es decir, la Constitución de la República, como norma suprema del ordenamiento jurídico ecuatoriano, es la que va a dar unidad y validez a las demás normas de menor jerarquía; por lo tanto, el principio de aplicación directa de la Constitución es dable siempre y cuando no exista norma legal que desarrolle un precepto constitucional; en el presente caso esa premisa no ocurre, ya que el Código de Trabajo, en sus artículos 452 y 512, establece los requisitos mínimos que deben cumplir los trabajadores para activar el aparato jurisdiccional, y si estas solemnidades y requisitos no se cumplen, como en el caso sub judice, esto es el cumplir con el número de trabajadores mínimos, esto no se debe considerar como mero formalismo, sino como solemnidades sustanciales, ya que esto determina el procedimiento específico que se debe seguir para el reclamo o reconocimiento de derechos.

El incumplimiento de esta clase de solemnidades violenta principios elementales del derecho al debido proceso, como es la prohibición de que nadie será juzgado por tribunales de excepción o por comisiones especiales creadas para el efecto, en el caso en análisis, consagrado en el literal k del numeral 7 del artículo 76 de la Constitución, ya que asumen una competencia que no está dada por la ley, así como tampoco ninguna jueza, juez o tribunal, a pretexto de principios de inmediación y celeridad, puede asumir jurisdicción de materia que no le corresponda. Estas situaciones vulneran el derecho a la seguridad jurídica, preceptuado en el artículo 82 de la Constitución de la República del Ecuador, que determina que las normas que formen parte del ordenamiento jurídico se encuentren determinadas previamente; además, deben ser claras y públicas; solo de esta manera se logra 
Acción extraordinaria de protección, el debido proceso, la seguridad jurídica, en las notificaciones procesales

conformar una certeza de que la normativa existente en la legislación será aplicada cumpliendo ciertos lineamientos que generan la confianza acerca del respeto de los derechos consagrados en el texto constitucional.

\section{Conclusiones}

El debido proceso en general fue introducido en la legislación mundial por primera vez en la declaración de los derechos del hombre y del ciudadano, adoptada por la Asamblea Nacional Constituyente de Francia el 26 de agosto de 1789, la cual en su artículo 7 dice: "Ningún hombre puede ser acusado arrestado y detenido sino en los casos determinados por la ley y las formalidades descritas en ello, los que solicite, expidan ejecuten o van a ejecutar ordenes arbitrarias, debe ser castigados, pero todo ciudadano llamado o preso en virtud de la ley debe obedecer al instante y si resiste se hace culpable". Principio fundamental que fue recogido en varios países en su legislaciones, pero sin embargo como narramos en el presente estudio de tesina, muchísimos años atrás en el año de 1251 el rey de ese entonces expidió la Carta Magna en la que se fundamentan en las primeras premisas para el debido proceso, luego la Suprema Corte de los Estados Unidos de América dice con razón: “ la historia de la observancia de las garantías procesales”, siendo así considero que nuestro país también recogido principios que nos hemos referido a lo largo de esta investigación por lo que desde un comienzo nuestra legislación consagra prestigio al derechos de los humano, pero sobre todo en materia penal, la garantía del debido proceso es la más amplia de todas las garantías consagradas en nuestra constitución dictada por la Asamblea Nacional en la cuidad de Montecristi con sus 444 artículos, y la que rige desde eso entonces el debido proceso en términos muy generales se determina que es un conjunto de normas que consagra derechos y garantías y protege a las personas de posibles abuso de autoridad pública siendo así un derecho fundamental de hombre entendiendo le al ser humano con el principio y el fin de todo sistema de organización 
estatal. Si revisamos nuestra historia desde que se inició la republica nuestro país ha tenido una colección de varias constituciones, DE TODO COLOR Y TENDENCIAS, en las que se consagran diferente principios y obedece a diferentes pensamientos de autoridades que en ese momento ejercen el poder, las mismas han sido acomodadas al gobernante de turno como en el presente caso, en donde una Asamblea Nacional se a entregado a la Presidencia de la Republica sin limitación Alguna y consiguiendo una descomposición total de la instituciones públicas como son Corte de Justicia, Corte Constitucional, Fiscalía, Contraloría, Procuraduría, sin fiscalización alguna, en donde la corrupción ha sido tan espantosa en Este gobierno que no se iguala a ninguno que hemos tenido a lo largo de la Republica, enumerarlos los actos de corrupción sería ocioso en este momento . Pero nos queda la esperanza de que en algún momento podamos escoger un verdadero estadista que pueda llevar a la prosperidad y bienestar a los ecuatorianos y podamos confiar plenamente en las instituciones. Luego de haber investigado y desarrollado este trabajo de esta tesina, he llegado a la conclusión de que el "El Debido Proceso" (derechoecuador.com, 2013) es trascendentalmente importante y vital para que las relaciones procesales, en cualquier marco de dignidad, humanidad, justicia y equidad. Para mí concepto el Debido Proceso Penal es un camino recto para llegar a la justicia verdadera, es el que permite que los principios del Derecho, como la legalidad, celeridad, economía, imparcialidad, oralidad se den estricto cumplimiento en trámite del Debido Proceso y se garantizan los derechos fundamentales de la persona, reconocidos por la Constitución, las Leyes, Pactos y Convenios Internacionales. Y no sean torcidos bajo ningún punto de vista ni interés, político, económico, moral, religiosa o étnico.- Es del todo claro que el principal interés que tiene el Estado a nivel interno y externo es la seguridad de sus habitantes. Esta seguridad es una garantía que se plasma con el Debido Proceso al momento de administrar justicia, dotando al acusado o inculpado de todas las garantías y derechos que por el hecho de ser persona los tiene, tratando de 
Acción extraordinaria de protección, el debido proceso, la seguridad jurídica, en las notificaciones procesales

brindarle toda la protección, seguridad y rehabilitación. Como también será el juez el garante de la constitución honrando de esta manera los principios básicos de la constitución, y aplicarlos sin miedo a nada ni nadie. Y por supuesto estudiando diariamente y capacitándose porque caso contrario sería fatal para los intereses de la saciedad.

También sería importante que el Estado sus instituciones, cuando no cumplan sus obligaciones y e impidan el libre goce de los derechos consagrados. A favor de las personas tienen reparar indemnizando por la acción u omisión de los actos, Repitiendo el pago, nombrando al mal funcionario que dicto su resolución o acto administrativo. Porque solo así podremos estar seguros de una eficaz, permanente, aplicación de los principios constitucionales. Y evitar de esta forma que la Constitución y sus derechos queden simplemente como papel como dice el tratadista italiano Ferrajoli.

Para concluir con el nuevo derecho procesal el juez de garantías tiene que tener una educación, doctrinaria, jurisprudencial, constitucional, legal e intelectual y convertirse en el verdadero ganarte en la aplicación de la ley.

\section{Bibliografía}

BIRF-4066-EC/ Editorial Javier Simancas, (1998).Loinianno, Adelina. Evolución de la doctrina de la Corte Interamericana.

Código orgánico de la función judicial

Código orgánico general del procesos

Constitución de la República del Ecuador.

De Derechos Humanos en materia de reparaciones". Foro Universidad de Chile USM.

Ferrajoli, Luigi, Derecho Razón, TEORIA DEL PROCESO, Editorial Trotta S.A., 6 Edición, (1995). 
Ley Orgánica de Garantías Jurisdiccionales y Control constitucional.

Projusticia. Debido proceso y razonamiento judicial. Quito, Convenio

www.derechoecuador.com.

www.lexis.com.consejo de la judicatura.

Zavala Baqurizo Jorge, debido proceso, segunda edición (2002) 